\title{
Importance of microhabitat selection by birds for the early recruitment of endangered trees in a fragmented forest
}

\author{
Ning $\mathrm{Li}^{i^{*}} \mathbb{D}$, Zheng Wang ${ }^{2}$, Yao Cai ${ }^{1}$ and Lin Zhang ${ }^{3}$
}

\begin{abstract}
Background: Remnant microhabitats are important for bird habitat selection and plant regeneration in the fragmented habitat. However, empirical information on the consequences of how microhabitat use by birds affects the early recruitment of plants is lacking.

Methods: In this study, we evaluated whether microhabitat selection by the Black Bulbul (Hypsipetes leucocephalus) (J. F. Gmelin, 1789) impacts the early recruitment of the endangered tree species, the Chinese Yew (Taxus chinensis (Pilger) Rehd), in a fragmented forest over a 4-year period (2011-2012, 2018-2019).

Results: Our results showed the main factors affecting $H$. leucocephalus microhabitat selection were distance to the nearest T. chinensis mature tree, herb cover and density, leaf litter cover, and vegetation type. Moreover, the results of logistic regression also highlighted the importance of elevation, distance to light gap and roads, tree cover in bird microhabitat selection. Furthermore, the seed emergence rate in microhabitats used by birds did not differ from the natural forest, which was related to five factors of bird microhabitat. The Random Forest model showed that seedling emergence rate was increased with leaf litter cover and distance to fallen dead trees, but decreased in relation to herb cover, slope, and elevation.

Conclusion: Our results highlight the importance of remnant microhabitats in fragmented forests for sustaining forest ecology and optimal management. The contribution of microhabitats used by birds to plant recruitment provides insights into how frugivore species contribute to plant regeneration, which should be incorporated in future conservation and management practices of fragmented forests.
\end{abstract}

Keywords: Fragmented forest, Hypsipetes leucocephalus, Microhabitat use, Seedling recruitment, Taxus chinensis

\section{Backgrounds}

Understanding how habitat fragmentation affects the persistence of plant populations is a central component of forest ecology and management (Taubert et al. 2018; Liu et al. 2019; Peters et al. 2019). In the case of fleshy-fruited trees, plant regeneration in remnant forest patches depends on the coupling of seed dispersal

*Correspondence: lining196@126.com

${ }^{1}$ Institute of Applied Ecology, Nanjing Xiaozhuang University, Nanjing 211171, Jiangsu, China

Full list of author information is available at the end of the article and seedling recruitment processes (Cordeiro and Howe 2003; Bregman et al. 2016; Farwig et al. 2017). Empirical evidence suggests that habitat fragmentation could disrupt plant regeneration by altering seed dispersal processes and reducing the availability of suitable microhabitat for regeneration (Bomfim et al. 2018; Emer et al. 2018; Simmons et al. 2018; Marjakangas et al. 2019). Nevertheless, the fundamental question remains of whether recruitment failure in fragmented forests is caused by a greater limitation of seeds available for dispersal or by post-dispersal processes (i.e., seedling establishment and 
germination) (Donoso et al. 2016; Schupp et al. 2017; García-Cervigón et al. 2018).

For bird-dispersed plants, birds transporting seeds away from the mother plants affect seed deposition in fragmented forests (Schupp et al. 2017; Li et al. 2020) and, hence, patterns of plant regeneration (Donoso et al. 2016; García-Cervigón et al. 2018). Often, birds exhibit complex behavioral pattern in response to forest fragmentation, depending on the distribution of food and other resources (e.g. shelter, nesting, vigilance or resting sites; Cody 1985; Côrtes and Uriarte 2013). For example, the loss of food resources by fragmentation might cause the number of frugivorous bird species to decline, thus reducing the amount of seeds removed and disrupting seed dispersal process (Pérez-Méndez et al. 2015; Farwig et al. 2017; Zwolak 2018). After foraging, birds often exhibit highly specific microhabitat selection. Consequently, a disproportionate number of seeds are deposited at sites selected by bird dispersers, negatively impacting future plant regeneration (Sasal and Morales 2013; Li et al. 2019).

Clearly, seed deposition patterns by birds depend on their behavioral decisions (Schupp 1993; Jordano and Schupp 2000; Cousens et al. 2010). Key behavioral processes include seed removal and post-foraging microhabitat use (Schupp et al. 2017). However, while the regeneration of plant populations in fragmented forest depends on where seeds are deposited by birds (Spiegel and Nathan 2007; Lehouck et al. 2009; Carlo et al. 2013), sites must also be suitable for the early regeneration of plants (Puerta-Piñero et al. 2012; Schupp et al. 2017). Although many studies have highlighted the role of birds in seed removal and seed deposition in fragmented forests (Farwig et al. 2017; Bomfim et al. 2018; Marjakangas et al. 2019), empirical evidence of the consequence of bird microhabitat use on seed germination in fragmented forests is lacking.

In Southeast China, the endangered Chinese Yew, Taxus chinensis (Pilger) Rehd, is a dominant tree species in fragmented forests, and it mainly depends on bird dispersal for regeneration ( $\mathrm{Li}$ et al. 2019). Over $80 \%$ seeds of T. chinensis were removed by the Black Bulbul, Hypsipetes leucocephalus (J. F. Gmelin, 1789) (resident species in Fujian, weight: 41-62 g), indicating that it is the most important species in T. chinensis-bird mutualism (Li et al. 2015). Here, we evaluated whether post-foraging microhabitat selection by $H$. leucocephalus impacts the early recruitment $T$. chinensis in a fragmented forest over a 4-year period (2011-2012, 2018-2019). Specifically, we examined: (1) which factors determine bird microhabitat use; and (2) how the microhabitat selection of $H$. leucocephalus impacts the early recruitment of $T$. chinensis in a fragmented forest. The results of this study are expected to demonstrate the importance of frugivores in facilitating the regeneration of tree species, with implications on conservation and management practices in remnant fragmented forests.

\section{Methods \\ Species and study site}

T. chinensis is a dioecious and wind-pollinated species that is distributed in evergreen broadleaf forests. Every year, female plants bear axillary cones which, in autumn, develop into fleshy arils (commonly, although incorrectly, referred to as "fruits") that contain a single seed. An average tree bears more than 4000 of these "fruits" (Li et al. 2015, 2019).

This study was conducted in a yew ecological garden (elevation 895-1218 $\mathrm{m}$ above sea level [a.s.l.], slope gradient $27^{\circ}$ ), located in the southern experimental area of the Meihua Mountain National Nature Reserve $\left(25^{\circ} 15^{\prime}-\right.$ $25^{\circ} 35^{\prime} \mathrm{N}, 116^{\circ} 45^{\prime}-116^{\circ} 57^{\prime} \mathrm{E}$ ) in the west part of Fujian Province, China. This site contains the largest natural population of $T$. chinensis in China (approximately 490 adults, distributed in the evergreen broadleaf forest), including 200 trees that are $>500$ years old. A national forest garden of 15 ha was established by the government in 2003 to protect these endangered trees. Due to long-term of human use, the vegetation around the forest garden is highly fragmented. The remnant evergreen broadleaf forest patch is interlaced with bamboo patches and mixed bamboo and broadleaf patches to form a fragmented forest. The dominant tree species of the remnant evergreen broad-leaved forest is T. chinensis (Additional file 1: Fig. S1).

\section{Microhabitat selection by Hypsipetes leucocephalus}

To study post-foraging microhabitat selection of $H$. leucocephalus, field observations were made after the birds departed mature $T$. chinensis plants. We observed the post-foraging perching position of $H$. leucocephalus using a field scope (Leica 70, Germany) at distances of 50-100 m from the opposite mountain slopes. When the position of birds was recorded, we collected regurgitated seeds in the canopy of bird preferred microhabitats (regurgitated seeds refer to cleaned seeds without any aril/coat that had been totally digested by birds). Because we tried to show the relationship between bird habitat use and plant recruitment, we chose the site with regurgitated seeds as bird-preferred microhabitat and set $1 \mathrm{~m} \times 1 \mathrm{~m}$ quadrats. To test whether bird selected habitat, we also set the quadrats in other available areas, and 
the position were confirmed by random number table. Totally, 30 used and 30 available quadrats were set to collect information on microhabitat factors in 2011. To exclude year-to-year variation in bird habitat selection, we recorded perching frequency at these 60 sites in the other study years (2012, 2018-2019).

In both bird-use and available quadrats, we measured three qualitative factors: aspect (shade slope; sunny slope), vegetation type (bamboo forest; Chinese Yew forest; farmland; mixed bamboo and broadleaf forest) and heterogeneous tree species (other tree species, except $T$. chinensis trees). Moreover, we also measured 15 quantitative factors: elevation, slope, distance to water, distance to light gap, distance to roads, distance to nearest T. chinensis tree, distance to nearest heterogeneous tree, distance to nearest $T$. chinensis mature tree, distance to fallen dead tree, herb cover, herb density, shrub cover, shrub density, tree cover, and leaf litter cover.

For analyzing microhabitat selection by birds, we first compared three qualitative factors by Chi square test. The other 15 quantitative factors evaluated between bird used, and available quadrats were first analyzed by a $t$-test. All quantitative variables were evaluated with Principal Component Analysis (PCA) based on their correlation matrix with a varimax rotation to screen out the key factors in microhabitat selection of $H$. leucocephalus. PCA is a multivariate technique that produces a simplified, reduced expression of the original data with complex relationships, and has been widely applied in studies of wildlife habitats (Fowler et al. 1998). We also used logistic regression to explore the role of microhabitat factors for bird habitat selection.

\section{Effects of microhabitat selection by birds on the early recruitment of Taxus chinensis}

Independent of the seed dispersal study, seedling emergence was assessed experimentally in 2017 and 2018 beneath the 30 sites used by $H$. leucocephalus. At each site, 200 seeds were sown at a depth of $1 \mathrm{~cm}$ to avoid predation by rodents. The germinated seedlings were monitored weekly from spring to fall of the following year. Plant early recruitment was computed as the fraction of germinated seedlings that survived to the end of the first fall.

To study the effects of bird microhabitat selection on the early recruitment of plants, we used the $t$-test to compare the seedling emergence rate in the fragmented forest with natural conditions (seedling emergence rate: $10.86 \%$, with 1000 seeds sowing under the canopy of 10 microhabitats in the natural habitat; Gao 2006). Random Forest model is an ensemble machine-learning method for classification and regression that operates by constructing a multitude of decision trees. It is appropriate for illustrating the nonlinear effect of variables, can handle complex interactions among variables and is not affected by multicollinearity. Random Forest can assess the effects of all explanatory variables simultaneously and automatically ranks the importance of variables in descending order. Then, we used the Random Forest (RF) algorithm to evaluate the quadrat habitat factors selected by birds in relation to the number of germinated seedlings ( $R$ package Random Forest) (Breiman 2001).

\section{Results}

After foraging, H. leucocephalus exhibited strong microhabitat selection. The Chi square test showed that vegetation type (Chi square test: $\chi^{2}=6.300, p=0.043$ ) and slope aspect (Chi square test: $\chi^{2}=9.600, p=0.002$ ) varied between microhabitats used by birds and those that were available. H. leucocephalus preferred shade slope and bamboo patches. Highly significant differences were detected between microhabitats used by birds and those that were available when considering distance to the nearest $T$. chinensis tree, distance to the nearest heterogeneous tree, distance to the nearest $T$. chinensis mature tree, shrub density, and leaf litter cover (Table 1).

Importantly, the PCA results highlighted that the main factors affecting $H$. leucocephalus microhabitat selection were distance to the nearest $T$. chinensis mature tree, herb cover, herb density, leaf litter cover, and vegetation type. Distance to light gaps and nearest heterogeneous trees were also important for bird microhabitat selection (Table 2). Moreover, the results by logistic regression

Table 1 Characteristics of $\boldsymbol{H}$. leucocephalus-preferred microhabitats and other available sites in the yew ecological garden representing a fragmented forest in Southeast China

\begin{tabular}{lcccc}
\hline Factor types & Preferred sites & Available sites & $\boldsymbol{t}$ & $\boldsymbol{p}$ \\
\hline Distance to Taxus chinensis tree & $16.273 \pm 10.999$ & $24.880 \pm 19.965$ & 2.068 & $0.043^{*}$ \\
Distance to Taxus chinensis mother tree & $22.240 \pm 17.076$ & $39.147 \pm 22.178$ & 3.308 & $0.002^{* *}$ \\
Shrub density & $0.567 \pm 0.858$ & $0.167 \pm 0.531$ & 2.171 & $0.034^{*}$ \\
Leaf litter cover & $0.630 \pm 0.267$ & $0.794 \pm 0.185$ & 2.772 & $0.007^{* *}$ \\
\hline
\end{tabular}

${ }^{*} p<0.05 ;{ }^{* *} p<0.01$ 
Table 2 Principal Component Analysis (eigenvalues $\geq 0.60$ ) for microhabitat factors used by Hypsipetes leucocephalus in the yew ecological garden representing a fragmented forest in Southeast China

\begin{tabular}{lrrrr}
\hline Factor types & PC1 & PC2 & \multicolumn{1}{c}{ PC3 } & \multicolumn{1}{c}{ PC4 } \\
\hline Elevation & 0.441 & 0.177 & 0.280 & 0.455 \\
Aspect & 0.205 & 0.090 & 0.242 & -0.345 \\
Slope & 0.281 & 0.593 & 0.157 & 0.012 \\
Distance to water & 0.109 & 0.362 & 0.394 & 0.549 \\
Distance to light gap & 0.133 & 0.733 & -0.043 & -0.318 \\
Distance to roads & 0.310 & 0.413 & 0.568 & -0.056 \\
Distance to Taxus chinensis tree & -0.505 & -0.118 & -0.022 & 0.560 \\
Type of heterogeneous tree & -0.183 & -0.269 & 0.801 & -0.019 \\
Distance to heterogeneous tree & 0.434 & -0.143 & 0.407 & -0.197 \\
Distance to Taxus chinensis mother & -0.665 & 0.157 & 0.232 & 0.236 \\
tree & & & & \\
Distance to fallen dead tree & 0.401 & -0.062 & -0.226 & 0.421 \\
Herb cover & 0.773 & -0.271 & 0.065 & -0.071 \\
Herb density & 0.664 & -0.221 & 0.321 & 0.119 \\
Shrub cover & 0.201 & 0.581 & -0.299 & -0.015 \\
Shrub density & 0.477 & 0.075 & -0.432 & 0.331 \\
Tree cover & -0.122 & 0.587 & -0.122 & -0.007 \\
Leaf litter cover & -0.616 & 0.255 & 0.291 & 0.080 \\
Vegetation type & -0.601 & 0.021 & 0.100 & -0.147 \\
Percentage of variance explained & 19.915 & 12.460 & 11.377 & 8.189 \\
(\%) & & & & \\
Cumulative percentage (\%) & 19.915 & 32.375 & 43.752 & 51.941 \\
\hline
\end{tabular}

Table 3 Results by logistic regression for microhabitat selection by Hypsipetes leucocephalus in the yew ecological garden representing a fragmented forest in Southeast China

\begin{tabular}{lcccc}
\hline Ecological factors & Coefficient $(\boldsymbol{B})$ & SE & Wald $\boldsymbol{X}^{\mathbf{2}}$ & Sig. \\
\hline Elevation & 0.110 & 0.045 & 5.882 & 0.015 \\
Distance to light gap & 0.626 & 0.261 & 5.739 & 0.017 \\
Distance to roads & -0.520 & 0.257 & 4.091 & 0.043 \\
Tree cover & -4.276 & 2.178 & 3.855 & 0.049 \\
Constant & -98.512 & 43.081 & 5.229 & 0.022 \\
\hline
\end{tabular}

showed habitat selection of birds was only affected by elevation, distance to light gap and roads, tree cover (Table 3; the other eleven factors did not affect habitat selection, All $p>0.05$ ).

As a consequence of bird habitat selection, the sowing experiment first showed a $5 \%-15.5 \%$ seedling emergence rate in the $H$. leucocephalus microhabitat, which was not significantly different from natural conditions $(t=1.679$, $p=0.104)$. Considering the seed germination related to habitat selection, the Random Forest model showed that seedling emergence rate increased with leaf litter cover and distance to fallen dead trees, but decreased in relation to herb cover, slope, and elevation (Random Forest: $62.43 \%$ of germinated seedlings could be explained by five variables) (Fig. 1).

\section{Discussion}

After foraging, H. leucocephalus exhibited strong microhabitat selection. Consequently, H. leucocephalus microhabitats influence the early recruitment of $T$. chinensis.

Because microhabitat characteristics vary in fragmented forests, they influence the microhabitat selection of birds. An optimum suitable microhabitat provides safe shelter for bird to avoid predation and an opportunity to access reliable food resources (Cody 1985). With forest fragmentation, the remnant microhabitat was important for the ecology and management of the fragmented forest. In our fragmented forest, bamboo patches and shrub density potentially supply safe shelter for $H$. leucocephalus. Microhabitats close to T. chinensis trees, heterogeneous trees, and $T$. chinensis mature trees could meet the two requirements of safety and food for $H$. leucocephalus. The requirement for optimum temperature is also an important component in the strategy of bird habitat selection (Moore 1945). Suitable microhabitat temperature is maintained by shrubs and herbs, providing shelter from wind and rain (Kelty and Lustick 1977; Cody 1985). In the current study, shrub density, distance to light gaps, herb cover, herb density, and leaf litter cover were preferred by $H$. leucocephalus, possibly because they supply suitable microhabitat temperature.

The remnant microhabitats selected by birds were important for plant recruitment (García-Cervigón et al. 2018). The seed emergence rate of $T$. chinensis beneath the microhabitats used by birds showed no significant difference to natural conditions; thus, $H$. leucocephalus is likely important for the early recruitment of $T$. chinensis. Furthermore, the emergence of $T$. chinensis seeds was influenced by bird microhabitat factors. Sites with low herb cover facilitated seed emergence, due to the low competitive ability of trees. T. chinensis (Li et al. 2015). Living with dense leaf litter cover could also provide an important supply of nutrients for seed germination. Because of the requirements for T. chinensis seedlings to germinate (Li et al. 2015), shaded slopes might supply a shaded microenvironment for seed germination.

\section{Conclusions}

This study demonstrated the microhabitats used by $H$. leucocephalus affected the early recruitment of $T$. chinensis. Our results also highlight the importance of remnant microhabitats in fragmented forest for 

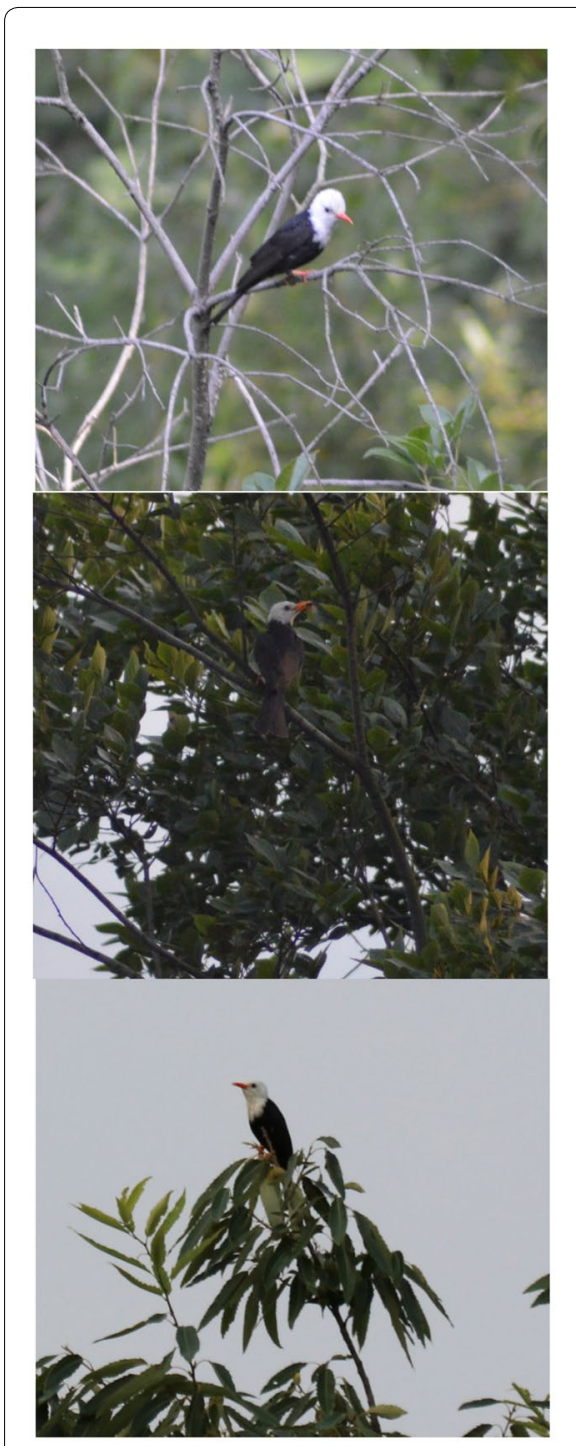

Microsite selection by Hypsipetes leucocephalus
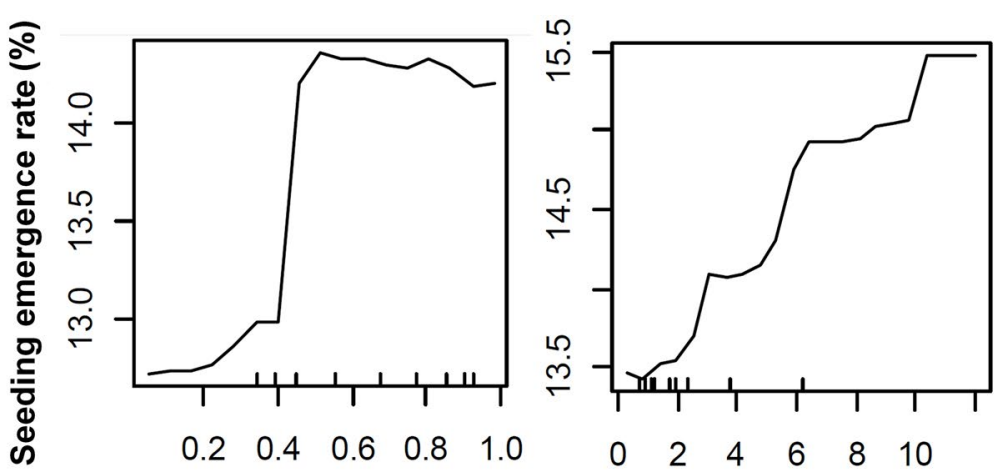

$\begin{array}{lllll}0.2 & 0.4 & 0.6 & 0.8 & 1.0\end{array}$
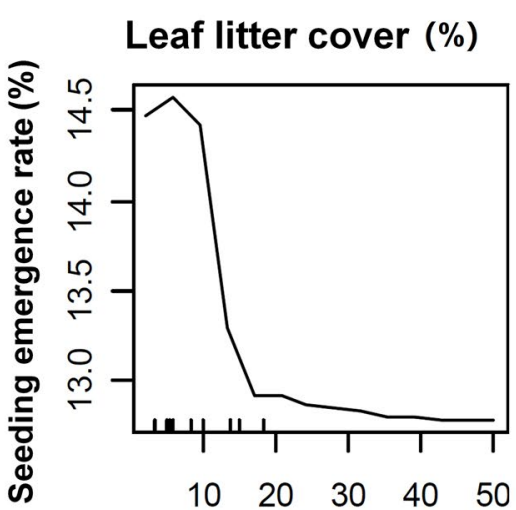

Herb cover (\%)

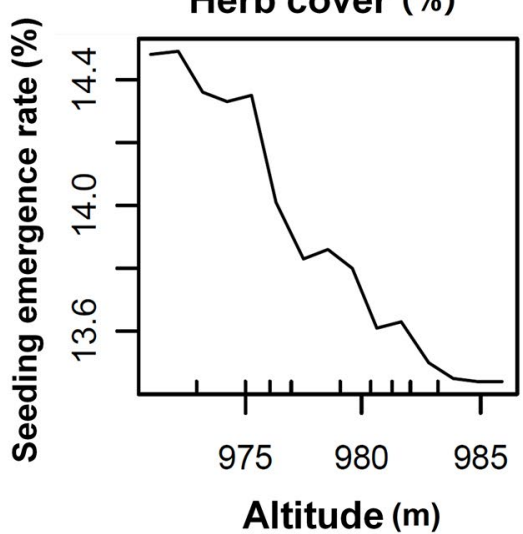

Fig. 1 Microhabitat selection by Hypsipetes leucocephalus and how these parameters (distance to fallen dead tree, distance to leaf litter cover, herb cover, slope, and elevation) affect the seedling emergence rate of Taxus chinensis in a yew ecological garden representing a fragmented forest in Southeast China. Results were determined using the Random Forest algorithm, and show the partial effects of the five independent variables on seedling emergence rate

sustaining forest ecology and enhancing management practices. The contribution of habitats used by birds to sites of plant recruitment could be used to determine how frugivore species facilitate plant regeneration. Such information could be incorporated in future conservation and management practices to facilitate the regeneration of fragmented forests. However, our study partially reflected the consequence of bird habitat selection on plant recruitment, owing to sowing the seeds in bird preferred habitat. Researchers need to consider in future studies including the sowing experiment in both bird preferred and available habitat with bird regurgitated seeds and natural fallen seeds. Furthermore, future studies also need to compare how bird habitat selection affect plant recruitment in both fragmented and continuous habitat, which could explore the effects of habitat fragmentation on bird-plant mutualism. 


\section{Supplementary information}

\section{Supplementary information accompanies this paper at https://doi.} org/10.1186/s40657-020-00232-7

\section{Acknowledgements}

We thank Shuai Zhang for providing assistance in the field. We also thank Prof. Xian-Feng Yi, Prof. Xin-Hai Li and Dr. Si-Chong Chen for constructive suggestions.

\section{Authors' contributions}

$\mathrm{NL}, \mathrm{ZW}$ and LZ conceived and designed this study. NL and ZW performed the study. NL and LZ analyzed the data. ZW and NL wrote the paper. All authors read and approved the final manuscript.

\section{Funding}

This study was supported by the National Natural Science Foundation of China (Grant No. 31700468) and the Natural Science Foundation of Jiangsu Province (Grant No. BK2017636).

\section{Availability of data and materials}

The datasets used in the present study are available from the corresponding author on reasonable request.

\section{Ethics approval and consent to participate}

Not applicable.

\section{Consent for publication}

Not applicable.

\section{Competing interests}

The authors declare that they have no competing interests.

\section{Author details}

${ }^{1}$ Institute of Applied Ecology, Nanjing Xiaozhuang University, Nanjing 211171, Jiangsu, China. ${ }^{2}$ College of Biology and Environmental Science, Nanjing Forestry University, Nanjing 210037, China. ${ }^{3}$ Hangzhou Key Laboratory for Animal Adaptation and Evolution, College of Life and Environmental Sciences, Hangzhou Normal University, Hangzhou 311121, China.

Received: 2 July 2020 Accepted: 2 November 2020

Published online: 01 December 2020

\section{References}

Bomfim JA, Guimarães PR, Peres CA, Carvalho G, Cazetta E. Local extinctions of obligate frugivores and patch size reduction disrupt the structure of seed dispersal networks. Ecography. 2018;41:1899-909.

Bregman TP, Lees AC, MacGregor HEA, Darski B, de Moura NG, Aleixo A, et al. Using avian functional traits to assess the impact of land-cover change on ecosystem processes linked to resilience in tropical forests. Proc R Soc B-Biol Sci. 2016;283:20161289.

Breiman L. Random forests. Mach Learn. 2001;45:5-32.

Carlo TA, García D, Martínez D, Gleditsch JM, Morales JM. Where do seeds go when they go far? Distance and directionality of avian seed dispersal in heterogeneous landscapes. Ecology. 2013;94:301-7.

Cody ML. Habitats selection in birds. London: Academic Press; 1985.

Cordeiro NJ, Howe HF. Forest fragmentation severs mutualism between seed dispersers and an endemic African tree. Proc Natl Acad Sci USA. 2003;100:14052-6.

Côrtes M, Uriarte M. Integrating frugivory behavior and animal movement: a review of the evidence and implication for scaling seed dispersal. Biol Rev. 2013;88:255-72.

Cousens RD, Hill J, French K, Bishop ID. Towards better prediction of seed dispersal by animals. Funct Ecol. 2010;24:1163-70.
Donoso I, García D, Rodríguez-Pérez J, Martínez D. Incorporating seed fate into plant-frugivore networks increases interaction diversity across plant regeneration stages. Oikos. 2016;125:1762-71.

Emer C, Galetti M, Pizo MA, Guimarães PR, Moraes S, Piratelli A, et al. Seeddispersal in a fragmented hotspot of biodiversity - a metanetwork approach. Ecol Lett. 2018;21:484-93.

Farwig N, Schabo DG, Albrecht J. Trait-associated loss of frugivores in fragmented forest does not affect seed removal rates. J Ecol. 2017;105:20-8.

Fowler J, Cohen L, Jarvis P. Practical statistics for field biology. 2nd ed. West Sussex: Open University Press; 1998.

García-Cervigón Al, Żywiec M, Delibes M, Suárez-Esteban A, Perea R, Fedriani JM. Microhabitats of seed arrival: spatio-temporal variations in complex seed-disperser networks. Oikos. 2018;127:1001-13.

Gao ZW. Research on Taxus chinensis var. mairei. Beijing: China Forestry Publishing House; 2006.

Jordano P, Schupp EW. Determinants of seed disperser effectiveness: the quantity component and patterns of seed rain for Prunus mahaleb. Ecol Monogr. 2000;70:591-615.

Kelty MP, Lustick SI. Energetics of the starling (Sturnus vulgaris) in a pine woods. Ecology. 1977:58:1181-5.

Lehouck V, Spanhove T, Vangestel C, Cordeiro NJ, Lenset L. Does landscape structure affect resource tracking by avian frugivores in a fragmented Afrotropical forest? Ecography. 2009;32:789-99.

Li N, Fang SB, Li XH, An SQ, Lu CH. Differential contribution of frugivorous birds to dispersal patterns of the endangered Chinese yew (Taxus chinensis). Sci Rep. 2015;5:10045.

Li N, Wang Z, Zhang S, Yan C, Li X, Lu C. Importance of bird traits for seed dispersal patterns of co-fruiting trees in a patchy forest. Integr Zool. 2019:14:470-8.

Li N, Zhang S, Ren YH, Wang Z. Importance of plant and bird traits on the seed removal pattern of endangered trees across different forest patches in southeast China. Ecol Process. 2020;9:43.

Liu J, Coomes DA, Gibson L, Hu G, Liu J, Luo Y, et al. Forest fragmentation in China and its effect on biodiversity. Biol Rev. 2019;94:1636-57.

Marjakangas EL, Abrego N, Grøtan V, de Lima RAF, Bello C, Bovendorp RS, et al. Fragmented tropical forests lose mutualistic plant-animal interactions. Divers Distrib. 2019;26:154-68.

Moore AD. Winter night habits of birds. Wilson Bull. 1945;57:253-60.

Pérez-Méndez N, Jordano P, Valido A. Downsized mutualisms: consequences of seed dispersers' body-size reduction for early plant recruitment. Perspect Plant Ecol. 2015;17:151-9.

Peters MK, Hemp A, Appelhans T, Becker JN, Behler C, Classen A, et al. Climateland-use interactions shape tropical mountain biodiversity and ecosystem functions. Nature. 2019;568:88-92.

Puerta-Piñero C, Pino J, Gómez JM. Direct and indirect landscape effects on Quercus ilex, regeneration in heterogeneous environments. Oecologia. 2012;170:1009-20

Sasal Y, Morales JM. Linking frugivore behavior to plant population dynamics. Oikos. 2013;122:95-103.

Schupp EW, Jordano P, Gómez JM. A general framework for effectiveness concepts in mutualisms. Ecol Lett. 2017;20:577-90.

Schupp EW. Quantity, quality and the effectiveness of seed dispersal by animals. Vegetatio. 1993;107:15-29.

Simmons BI, Sutherland WJ, Dicks LV, Albrecht J, Farwig N, García D, et al. Moving from frugivory to seed dispersal: incorporating the functional outcomes of interactions in plant-frugivore networks. J Anim Ecol. 2018:87:995-1007.

Spiegel O, Nathan R. Incorporating dispersal distance into the disperser effectiveness framework: frugivorous birds provide complementary dispersal to plants in a patchy environment. Ecol Lett. 2007;10:718-28.

Taubert F, Fischer R, Groeneveld J, Lehmann S, Müller MS, Rödig E, et al. Global patterns of tropical forest fragmentation. Nature. 2018;554:519-22.

Zwolak R. How intraspecific variation in seed-dispersing animals matters for plants. Biol Rev. 2018:93:897-913. 